\title{
Prevalence of Life Style risk factors among a sample of Hypertensive Patients in Al-Hussain Teaching Hospital during
} 2016

\author{
Nawras Abdullah Khudaeer1 ${ }^{1}$ \& Dr. Muslim Nahi Saeed ${ }^{2}$ \\ ${ }^{1}$ Al-Hussien Teaching Hospital, Directorate of Health, Thi-Qar, Iraq. \\ ${ }^{2}$ Thi-Qar University-College of Medicine,Thi-Qar, Iraq. \\ Muslim-na@utq.edu.iq ${ }^{2}$
}

\begin{abstract}
Background: Hypertension is the prominent cause of early death in the world and the number of population with hypertension is developing. It is a preventable risk factor for stroke, myocardial infarction, heart failure, peripheral vascular disease, aortic dissection, atrial fibrillation, and end-stage kidney disease.
\end{abstract}

Aim of Study: General Objective: To assess the extent of life style modifications among hypertensive patients.

Specific Objectives:

1. To measure the awareness of hypertensive patients about life style modifications.

2. To investigate the status of adherence to life style modifications among hypertensive patients.

Methodology: The study was an analytical cross sectional study for 576 hypertensive patients who had intended Al-Hussain teaching hospital in Nasiriya city during the period from the first of January 2016 to the end of September 2016.

The study population included all patients aged 25 years and above of both sexes with previous diagnosis of hypertension made by medical staff. While the exclusion criteria included those who were not aware that they have hypertension, all pregnant women with gestational hypertension were also excluded.

Conclusion: This study reveals that there is a poor level of awareness of lifestyle modification which is needed in the management of hypertension among a representative sample of adult hypertensive patients how attended Al-Hussain teaching hospital.

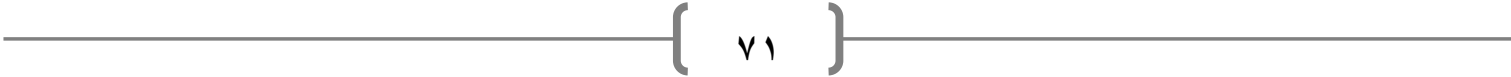


guidelines for the management of hypertension recommends lifestyle modification for all patients with hypertension (that is, blood pressure of

\section{Introduction}

Hypertension, or what called ( high blood pressure BP), can be defined as systolic blood pressure (SBP) equal to or higher than $140 \mathrm{mmHg}$, or diastolic blood pressure (DBP) equal to or higher than $90 \mathrm{mmHg}^{(1,2,3)}$. Hypertension has been named the silent killer, and is characterized by an asymptomatic chronic health condition that silently damages the blood vessels, heart, brain, and kidneys if it is undetected and untreated ${ }^{(2)}$. It is a preventable risk factor for stroke, myocardial infarction, heart failure, peripheral vascular disease, aortic dissection, atrial fibrillation, and end-stage kidney disease $^{(3)}$. Global burden, nearly one billion people have hypertension (3); of these, two thirds in developing countries. Hypertension ranks first among the non-communicable diseases in Nasiriya city with high prevalence in reported series. A recent community based study of rural and semi urban population in Nasiriya city put the prevalence of hypertension in Nasiriya city at $35.6 \%$ (4), whereas the prevalence of hypertension in Iraq is $40 \%{ }^{(5)}$.Despite all that is known about its adverse health consequences, Hypertension is still poorly controlled in Nasiriya city. The Seventh Report of the Joint National Committee on Prevention, Detection, Evaluation, and Treatment of Hypertension (JNC-7)
$14 \mathrm{o} / 9 \mathrm{o} \mathrm{mm} \mathrm{Hg}$ or more) or prehypertension (that is, blood pressure of $120 / 80$ to $139 / 89 \mathrm{mmHg})^{(6)}$. These modifications, previously referred to as non-pharmacologica1 treatment, serve as coordinated therapy for hypertension and encompass weight reduction, increased physical activity, reduction of dietary sodium and alcohol intake and following the Dietary Approach to Stop Hypertension (DASH) eating plan ${ }^{(7)}$.

Patient's awareness of blood pressure plays animportant roles in the ability to successfully control hypertension ${ }^{(8,9)}$. A previous study showed an association between hypertension awareness and compliance in patients with hypertension ${ }^{(10)}$.Importance of lifestyle modifications for hypertension management is as the following;First, lifestyle modifications are advised as first-line therapy ${ }^{(11)}$ and are suggested in every treatment regimen $^{(2)}$. A treatment regimen with only pharmacological therapy, and without lifestyle modifications, is less effective. Second, in hypertensive individuals with pharmacological therapy-controlled BP, lifestyle modifications can facilitate drug stepdown, and potentially, drugcessation $^{(12)}$.

\section{Patients and Methods}




\section{Type of study:-}

The study was an analytical cross sectional study for 576 hypertensive patients who had intended Al-Hussain teaching hospital in Nasiriya city during the period from the first of January 2016 to the end of September 2016.

\section{Study Population:-}

The study population included all patients aged 25 years and above of both sexes with previous diagnosis of hypertension made by medical staff. While the exclusion criteria included those who were not aware that they have hypertension, all pregnant women with gestational hypertension were also excluded.

\section{Collection of Sampling:-}

The blood pressure status was assessed by measuring the average of two reading of blood pressure by using sphygmomanometer at heart level using appropriate cuff size. The subjects were allowed to relax for 3-5 minutes in a sitting position before assessment of BP. The patient body weight was measured by balance weight, height and waist circumference were measured by tap measure and body mass index was calculated as Body weight in kilograms divided by height in meters squared. In addition, the patient adherence to the individual item of life style modifications had been investigated by a special questionnaire designed for the purpose of this study. It included personal and sociodemographic information such as name, age (years), sex (male and female), marital status (single, married ,divorced or widow), occupation (health professionals, engineering professionals, teaching professionals, employed, self -employed, students, retired and unemployed or house-wife) and socioeconomic characteristics: monthly income (less than 250000 Iraqi Dinar, 250000-500000 Iraqi Dinar and more than 500000 Iraqi dinar) and socioeconomic index. The socioeconomic index was classified according to the following scoring: 1presence of owned or rented house (scored as 1). 2-presence or absence of private car (scored as 1). 3-the number of electric appliances in household (up to $2=1,3$ to $5=2,6$ or more $=3$ ). An overall socioeconomic index score was calculated for each subject: a score of 2 or less indicated low socioeconomic status and a score 3-4 was defined as moderate, and $>4$ was considered as high socioeconomic status. Also it included duration of hypertension $(\leq 1$, $1-9,10-19, \geq 20$ years).

Also, the questionnaire included asking about smoking (smoker, not smoker, ex-smoker and negative smoking), asking about Alcohol intake (yes or no) and when the answer was yes then asking about the number of years of Alcohol consumption. It contained asking about salt intake but there was a limitation of measure the exact amount of salt intake so that the questions to the patients weather they have an especial meal without salt, they ate with their family or add excess amount of salt), then asking about fat 
intake which was also difficult to identify the real amount that the patient had taken so that also the questions to the patients weather they have an especial meal without oil or they ate with their family).It contained asking about fruits and vegetables intake(less than two servings per day, two to five servings per day, more than five servings per day or none). Also it included asking about exercise (yes or no) and if the answer was yes asking about the type o exercise (brisk walking, swimming, cycling, football or aerobic exercise).

\section{Statistical Analysis:}

Data were analyzed using Statistical Package of Social Science (SPSS) version 23.0. Quantitative data were expressed as mean \pm standard deviation (SD). Qualitative data were expressed as frequency and percentage. Chi -square, P-value (was consider significant at level of 0.05), Fisher exact test were used in this study 
Thi-Qar Medical Journal (TQMJ): Vol.(12), No.(2), 2016

\section{Results}

Table (1): Distribution of Hypertensive Patients According to taking anti-hypertensive drugs. Table 1: shows that there is a highly significant statistical association between distribution of patients according to their line of management and blood pressure class.

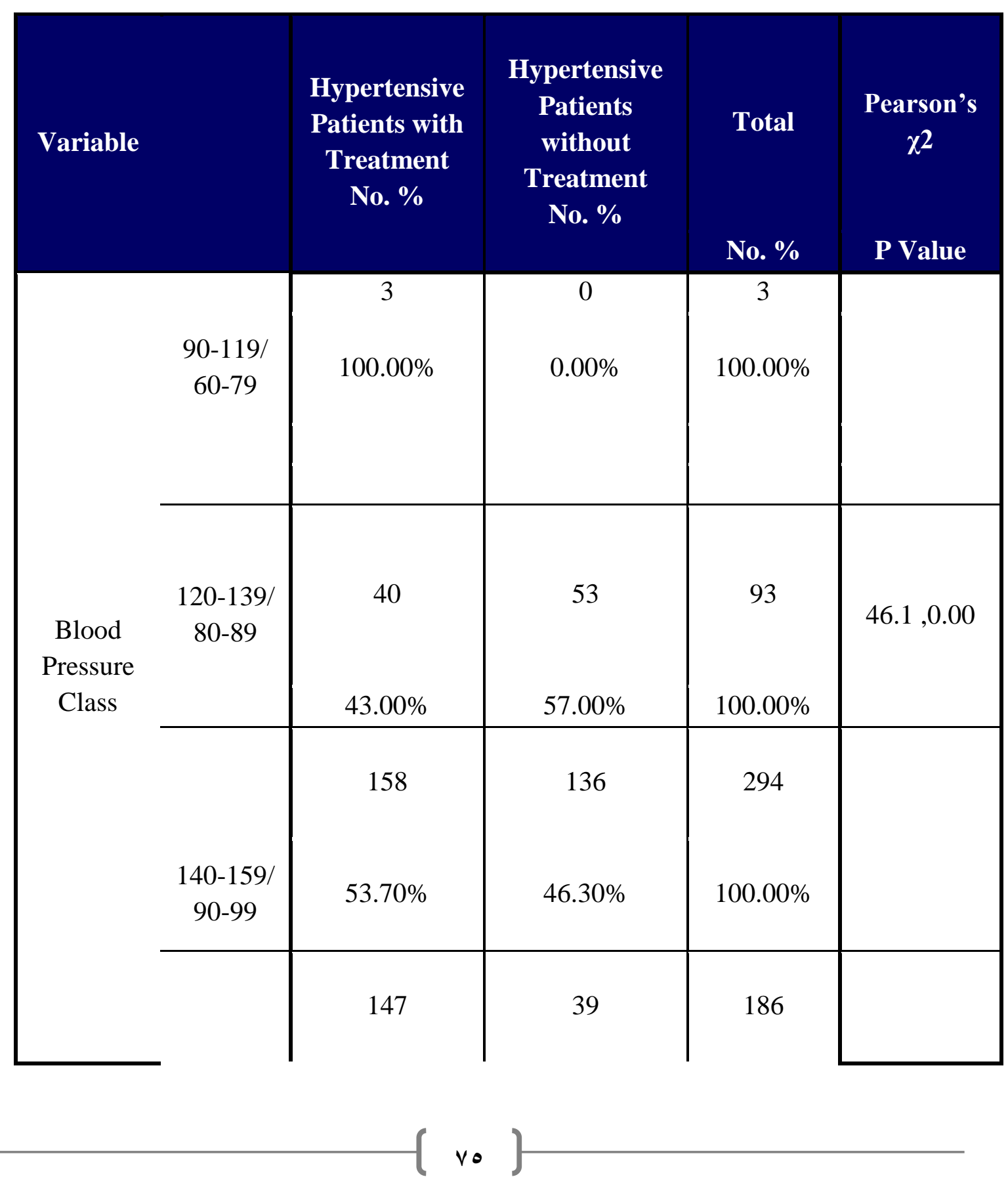


Thi-Qar Medical Journal (TQMJ): Vol.(12), No.(2), 2016

Email:utjmed@utq.edu.iq

Web Site: https://jmed.utq.edu.iq

\begin{tabular}{|l|l|l|l|l|}
\hline $160-180 /$ & & & & \\
$100-120$ & $79.00 \%$ & $21.00 \%$ & $100.00 \%$ & \\
\hline
\end{tabular}

Table (2): Bivariate correlation of systolic and diastolic blood pressure, age, sex, occupation, marital status and socio- economic state of raw data $(n=576)$ Table 2: shows that SBP and DBP are positively correlated with age, occupation and marital state but. No statistical significance correlation is found in the among SBP, DBP, sex and socio economic state. 
Thi-Qar Medical Journal (TQMJ): Vol.(12), No.(2), 2016

\begin{tabular}{|c|c|c|c|c|c|c|c|}
\hline & $\begin{array}{c}\text { Systolic } \\
\text { BP }\end{array}$ & $\begin{array}{c}\text { Diastolic } \\
\text { BP }\end{array}$ & Age & Sex & Occupation & $\begin{array}{c}\text { Marital } \\
\text { status }\end{array}$ & $\begin{array}{c}\text { Socio- } \\
\text { economic } \\
\text { State }\end{array}$ \\
\hline Systolic BP & 1 & & & & & & \\
\hline Diastolic BP & $.879 * *$ & 1 & & & & & \\
\hline Age & $.426 * *$ & $.432 * *$ & 1 & & & & \\
\hline Sex & 0.058 & -0.019 & 0.071 & 1 & & & \\
\hline Occupation & $.180 * *$ & $.207 * *$ & $\begin{array}{r}.281 * \\
*\end{array}$ & $.146^{* *}$ & 1 & & \\
\hline Marital Status & $.418^{* *}$ & $.328 * *$ & $\begin{array}{r}.384 * \\
*\end{array}$ & $.188 * *$ & $.095 *$ & 1 & \\
\hline $\begin{array}{l}\text { Socio- } \\
\text { economic } \\
\text { State }\end{array}$ & 0.04 & -0.006 & -0.03 & -0.026 & 0.005 & 0.014 & 1 \\
\hline
\end{tabular}

Table (3): Bivariate correlation of systolic blood pressure, diastolic blood pressure, BMI, salt intake, fat intake, fruit and vegetable intake, smoking and exercise of raw data (n = 576). Table 3: shows that systolic blood pressure and diastolic blood pressure are positively correlated with BMI and but negatively correlated with salt intake, fat intake and fruit and vegetable intake. Systolic and diastolic blood pressure also are positively 
Thi-Qar Medical Journal (TQMJ): Vol.(12), No.(2), 2016

Email:utjmed@utq.edu.iq

Web Site: https://jmed.utq.edu.iq

correlated with smoking and exercise. There is positive correlation between systolic and diastolic blood pressure.

\begin{tabular}{|c|c|c|c|c|c|c|c|c|}
\hline & $\begin{array}{c}\text { Systolic } \\
\text { BP }\end{array}$ & $\begin{array}{c}\text { Diastolic } \\
\text { BP }\end{array}$ & BMI & $\begin{array}{c}\text { Salt } \\
\text { Intake }\end{array}$ & $\begin{array}{c}\text { Fat } \\
\text { Intake }\end{array}$ & $\begin{array}{c}\text { Fruit and } \\
\text { Vegetables } \\
\text { Intake }\end{array}$ & Smoking & Exercise \\
\hline $\begin{array}{c}\text { Systolic } \\
\text { BP }\end{array}$ & 1 & * & & & & & & \\
\hline $\begin{array}{c}\text { Diastolic } \\
\text { BP }\end{array}$ & $.879^{* * *}$ & 1 & & & & & & \\
\hline BMI & $.419^{*}$ & $.310^{m}$ & 1 & & & & & \\
\hline Salt Intake & $-.369^{* *}$ & $-.324^{* *}$ & $-.234^{* *}$ & 1 & & & & \\
\hline Fat Intake & -0.075 & -0.062 & $-.155^{* *}$ & $.251^{* *}$ & 1 & & & \\
\hline $\begin{array}{c}\text { Fruit and } \\
\text { Vegetables } \\
\text { Intake }\end{array}$ & $-.335^{* *}$ & $-.319^{* *}$ & $-.146^{* *}$ & $.163^{* *}$ & $.153^{* *}$ & 1 & & \\
\hline Smoking & $.141^{* *}$ & $.175^{* *}$ & 0.015 & $-.163^{* *}$ & -0.074 & -0.056 & 1 & \\
\hline Exercise & $.317^{* * *}$ & $.334^{* * *}$ & $.216^{* *}$ & -0.049 & 0.007 & $-.205^{* *}$ & 0.007 & 1 \\
\hline
\end{tabular}

Discussion

Outcomes of Adherence to Lifestyle Modifications among Hypertensive Patients:
BP Classes in People with Hypertension

The percentage of pre

hypertensive patients $(16.1 \%)$, the 
percentage of patients with stage-1 hypertension $(51.0 \%)$ and the percentage of stage-2 hypertensive patients $(32.2 \%)$ in this study are much higher than that reported in previous national or provincial surveys(Gao et al., 2013; Wang et al., 2013; Wang et al., 2014) (13, 18, 21). The reason for the higher blood pressure levels found in this study may be related to the type of sample. All of the participants recruited in this study are from Al-Hussain teaching hospital, whereas the participants recruited in the previous survey were from the general population, who may or may not have attended hospitals.So, the difference in participants between this study and previous surveys might explain the gap of percentage of BP average readings.

\section{Relationship Between Age and Gender, and Adherence to Lifestyle Modifications}

The results of the model-fit test find that age influenced adherence by mediating the effect of self-efficacy. Previous studies (Svetkey et al., 2005) ( $1 \leqslant$ ) have found positiveor(Bouchard et al., 2012) (15) whichhave found negative associations between age and adherence

to lifestyle modifications. This study points out that age is directly associated

with adherence. Rather, the effect of age first impacts self-efficacy, which then affects the level of adherence. So, compared with previous studies, this study identifies self-efficacy as the mediator of the association between age and adherence, and therefore provides a more comprehensive understanding on the effect of age on adherence.

Previous studies(Lee et al., 2010; Yang et al., 2014; Yoo, Kim, Jang, \& You, 2011) $(16,19,20)$ have found inconsistent results about the correlation between age and self-efficacy in people with hypertension In this study, the positive correlation between age and self-efficacy indicates that older people with hypertension tend to have more confidence in adhering to lifestyle modifications than younger patients. There are three possible reasons for this result. First, older patients may perceive more threats of hypertension than younger patients because of organ functional decline in old age. They are more likely to conduct LSM than younger patients in response to the threats. Second, most of older patients are retired and have much more opportunities to modify their unhealthy lifestyles than younger patients (17). For example, compared with employed young patients, retired older patients are less likely to eat salty and oily food at business functions.

In this study, multiple group modelling shows no difference in the mode1-fit test between males and females, but the correlation between age and self-efficacy in the model is statistically significant for males (females were non-significant).

This result shows that gender influences adherence to lifestyle modifications by moderating the effect of age on self-efficacy. That is, older male patients have more confidence in conducting lifestyle modifications than 
younger male patients, whilst there is no difference in the confidence between patients in females. The reasons for this result are not clear, although possible explanations can be that when people are young and employed, males would more likely follow unhealthy lifestyles (large salty and oily meals, drinking and smoking) at business functions than females. As people get older and retire from the workplace, the unhealthy lifestyles for business purposes disappeared. So, the changes of external factors (i.e. business purposes), along with age, influence the confidence in modifying lifestyles in males more than females.

\section{The Effect of Lifestyle Modifications on BP and BMI Levels}

\section{General Information of $B P$ and $B M I$ Levels}

This study measures SBP, DBP and BMI to evaluate the outcomes of lifestyle modifications. These outcomes reflect the efficiency of adherence to lifestyle modifications(Svetkey et al., 2005) ( $1 \varepsilon)$. Different lifestyles due to regional differences and financial development may be the reason for the different BP levels. In this study, 41.6\% people with hypertension are overweight and $49.9 \%$ are obese according to WHO criteria for BMI classification. Previous study (Wang et al., 2013)(18) reports $68.55 \%$ of people with hypertension are overweight or obese. As a result, there is a great necessity to improve the leve 1 of adherence to lifestyle modifications for enhancing the contro1 of hypertension.

\section{Conclusion}

This study reveals that there is a poor level of awareness of lifestyle modification which is needed in the management of hypertension among a representative sample of adult hypertensives how attended Al-Hussain teaching hospital. Among those with some level of awareness, the practice is relatively poor. Measures need to be taken to improve both knowledge and practice of this non-pharmacological aspect of patients care. Barriers to successful practice need to be identified. Correct measures need to be taken from the point of diagnosis of hypertension or pre-hypertension by the doctors or other members of the health care team.

\section{References}

1. James, P. A., Oparil, S., Carter, B. L., \& et al. (2013). 2014 evidence-based guideline for the management of high blood pressure in adults: Report from the panel members appointed to the eighth joint national committee (jnc 8). JAMA. doi: 10.1001/jama.2013.284427.

2. Victor, R.G. Chapter 67 Arterial Hypertension. In L. Goldman \& A. I. Schafer (Eds.), Goldman's Cecil Medicine (24th ed., pp. 373-389). Philadelphia, PA: Elsevier Saunders (2011).

3. World Health Organization Regional Office for South-East Asia. Hypertension Fact sheet. Retrieved 12 March, 2015, from http://www.searo.who.int/entity/noncom 
municable_diseases/media/non_communi cable_diseases_hypertension_fs.pdf.2011 4. WHO step wise for Noncommunicable diseases risk factor survey in Iraq 2015.

5. WHO step wise for Noncommunicable diseases risk factor survey in Iraq 2005.

6. Chobanian AV, Bakris GL, Black HR, Cushman WC, Green LA, Izzo JL Jr, Jones DW, Materson BJ, Oparil S, Wright JT. Seventh report of the Joint National Committee on Prevention, Detection, Evaluation, and Treatment of High Blood Pressure. Journal of the American Medical Association 2003; 289:19:2560-2572

7. Guidelines for the management of hypertension in Nigeria May 1996. Available at www.nigerianheart.org. Accessed on $24^{\text {th }}$ November 2013 by 7.25 pm

8. Wizner B, Grodzicki T, Gryglewska B, Kocemba $\mathbf{J}$ and GrodzickiT. Knowledge about hypertension and blood pressure level [in Polish]. PrzeglLek 2000; 57:402- 405

9. Alexander M, Gordon NP, Davis CC, Chen RS. Patient knowledge and awareness of hypertension is suboptimal: results from a large health maintenance organization; J ClinHypertens (Greenwich) 2003;5:254-260.

10. Balazovjech I, Hnilica P (Jr). Compliance with antihypertensive treatment in consultation rooms for hypertensive patients. J Hum Hypertens 1993; 7:581-583.

11. Lochner, J., Rugge, B., \&Judkins, D. How effective are lifestyle changes for controlling hypertension? Journal of Family Practice, 2006; 55(1), 73-74.
12. Appel, L.J. Lifestyle modification: is it achievable and durable? The argument for. Journal of Clinical Hypertension (Greenwich, Conn.), 2004; 6(10), 578-581.

13. Gao, Y., Chen, G., Tian, H., Lin, L., Lu, J., Weng, J. Yang, W. (2013). Prevalence of hypertension in china: a cross-sectional Fukutomi, M., \&Kario, K. (2010). Aging and hypertension. Expert Review Of Cardiovascular Therapy

14. Svetkey, L. P., Sacks, F. M., Obarzanek, E., Vollmer, W. M., Appel, L. J., Lin, P. H., . . . Laws, R. L. (1999). The DASH Diet, Sodium Intake and Blood Pressure Trial (DASH-sodium): rationale and design. DASH-Sodium Collaborative Research Group. Journal of the American Dietetic Association, 99(8 Suppl), S96-S104. 15. Bouchard, D. R., Langlois, M.-F., Domingue, M.-È., Brown, C., LeBrun, V., \&Baillargeon, J.-P. (2012). Age Differences in Expectations and Readiness Regarding Lifestyle Modifications in Individuals at High Risk of Diabetes. Archives of Physical Medicine and Rehabilitation, 93(6), 10591064.doi:http://dx.doi.org/10.1016/j.apmr.20 11.12.028.

16. Lee, J.-E., Han, H.-R., Song, H., Kim, J., Kim, K. B., Ryu, J. P., \& Kim, M. T. (2010). Correlates of self-care behaviors for managing hypertension among Korean Americans: A questionnaire survey. International Journal of Nursing Studies.

17. Chen, J., \& Chen, G. (2009). Explorative and comparative analysis of lifestyles between employed and retired population in Beijing City. Sport, 1(2), 130132. (In Chinese).

18. Wang, H., Zhang, X., Zhang, J., He, Q., Hu, R., Wang, L., . . . Ye, Z. (2013). 


\section{Email:utjmed@utq.edu.iq}

Factors associated with prevalence, awareness, treatment and control of hypertension among adults in Southern China: a community-based, cross-sectional survey.

19. Wang, J., Zhang, L., Wang, F., Liu, L., \& Wang, H. (2014). Prevalence, Awareness, Treatment, and Control of Hypertension in China: Results From a National Survey. Am J Hypertens, 27(11), 1355-1361. doi: 10.1093/ajh/hpu053.
Web Site: https://jmed.utq.edu.iq

20. Yoo, H., Kim, C. J., Jang, Y., \& You, M.-A. (2011). Self-efficacy associated with self-management behaviours and health status of South Koreans with chronic diseases. International Journal Of Nursing Practice, 17(6), 599-606. doi: 10.1111/j.1440172X.2011.01970Maniecka-Bryla, I., Szymocha, M., \&Bryla, M. (2011). Overweight and obesity as risk factors in hypertension--study of the working population. 


\section{مدى انتشار عوامل الخطورة المتعلقة بنمط الحياة لعينة من مرضى ارتفاع ضغط الدم في مستشفى الحسين التطليمي

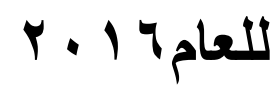 \\ نورس عبدالله خضير \\ مسلم ناهي سعيد}

الخلاصة :

خلفية الدراسة : إن مرض ارتفاع ضغط الدم هو أحد الأسباب الرئيسية لما يسمى بالموت المبكر في

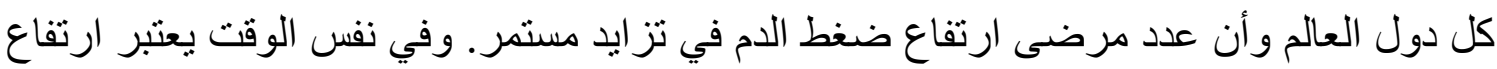

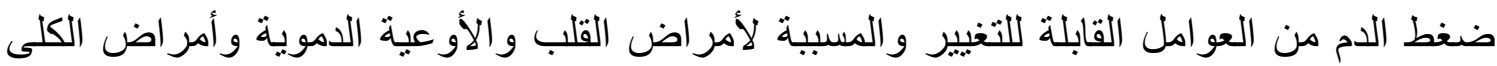

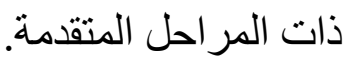

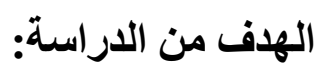
الههف العام : لمعرفة مدى انتشار طرق تكيف النمط المعيشي لمرضى ارتفاع ضغط الدم.

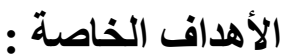

ا:لقياس مدى وعي مرضى ارتفاع ضغط الدم حول أهمية استخدام طرق تكيف النمط

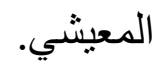
r:لتحليل وتقييم أداء مرضى ارتفاع ضغط الدم لطرق تكيف النمط المعيشي.

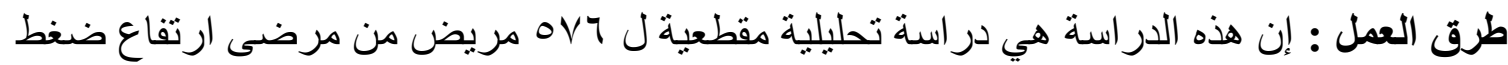

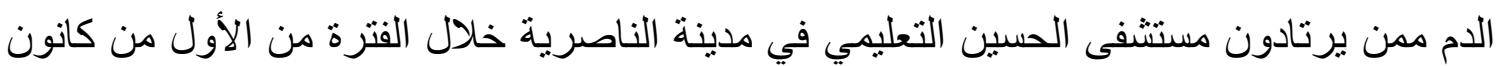

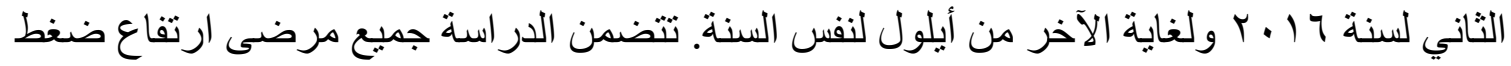

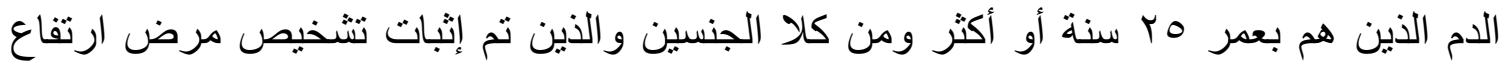

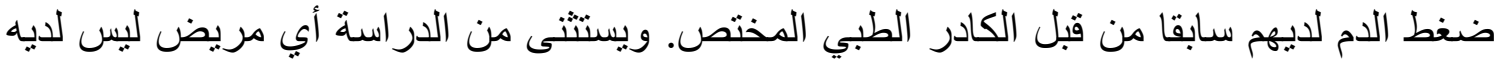

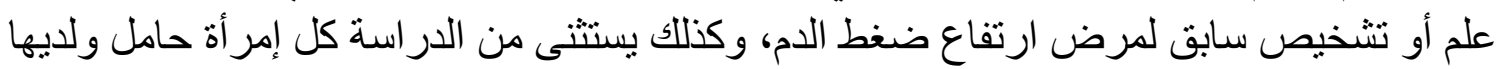
مرض ارتفاع ضغط الدم بسبب الحمل.

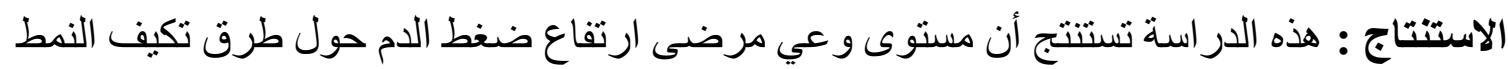

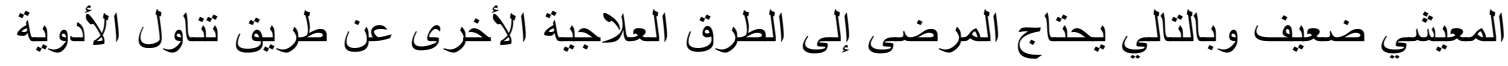

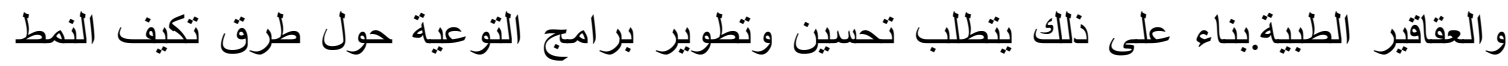

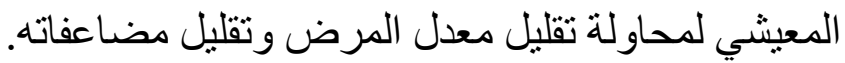

